\title{
The relationship between religiosity and moral foundations with substance abuse tendency in 15 to 18-years female students in Tehran
}

\author{
Mahdiyeh Shooshtari Rezvani ${ }^{1}$, Naser Aghababaei ${ }^{2 *}$ \\ 1. Islamic Azad University, Electronic Branch, Tehran, Iran \\ 2. The Institute for Research and Development in the Humanities (SAMT), Tehran, Iran
}

Received: 5 September 2020

Accepted for publication: 6 February 2021

[EPub a head of print-22 February 2021]

Payesh: 2021; 20 (1):119-125

\begin{abstract}
Objective (s): Addiction (substance addiction) is considered as one of the health issues which can influence physical, emotional and social aspects of people's life and impose psychosocial problems for their families and communities. Accordingly, this study aimed to investigate the relationship between religiosity and ethical foundations with substance abuse tendency among young female students in Tehran, Iran.

Methods: This cross-sectional study was performed on a sample of female students aged 15 to 18 years in Tehran, Iran. Statistical population consisted of 241 girls who were selected with systematic non-probability sampling and available in the first semester of academic year in 2019-2020 and respond to three questionnaires including the Ethical Foundations Scale and the Addiction Tendency Scale and the Religiosity Scale. Spearman correlation coefficient and regression were used to analyze the data using SPSS software.

Results: The results obtained from the analysis showed that religiosity and moral foundations with substance abuse tendency significant were correlated $(\mathrm{p}<0.01)$. In addition, the findings showed that religiosity and moral foundations predicted a total of $17 \%$ of changes to substance abuse among girls. Furthermore, among subscales of the religiosity, the outcome of being a Muslim $(r=-0.35)$ and among the subscales of moral foundations, loyalty to a group $(-=0.28)$ had the most significant relationship.

Conclusion: The finding suggest that religiosity and moral foundations can play a major role in reducing high-risk behaviors, especially addiction, in adolescent girls.
\end{abstract}

Key Words: Religiosity, moral foundations, addiction, adolescents

\footnotetext{
* Corresponding author: The Institute for Research and Development in the Humanities

E-mail: naseragha@gmail.com
} 


\title{
رابطة ديندارى و بنيانهاى اخلاقى با كرايش به اعتياد در دختران ها تا \ل سالهُ شهر تهران
}

\author{
مهديه شوشترى رضوانى ؛ ناصر آقابابايى ؟* \\ ا. ا. دانشعاه آزاد اسلامى واحد الكترونيكى، تهران، ايران

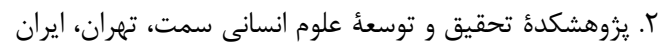

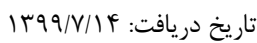

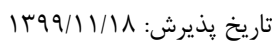

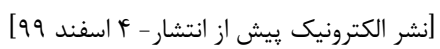

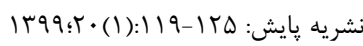

جكيده

مقدمه: اعتياد يك بيمارى جسمى و روانى است كه مى تواند همه ابعاد سلامت فرد، خانواده و جامعه را به خطر اندازد. طى سالهاى اخير مصـرف

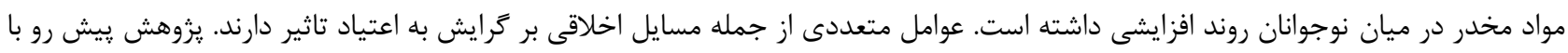

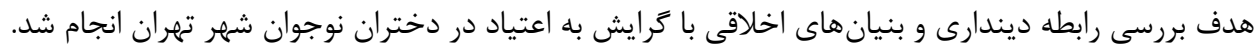

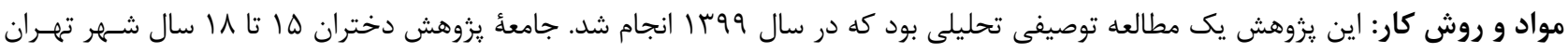

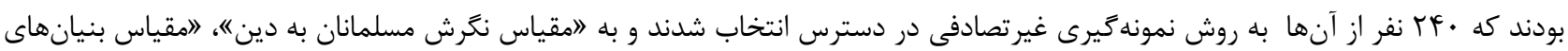

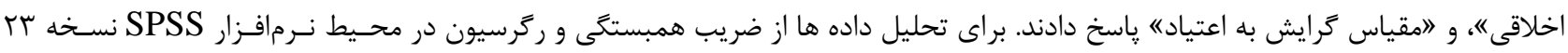
استفاده شد.

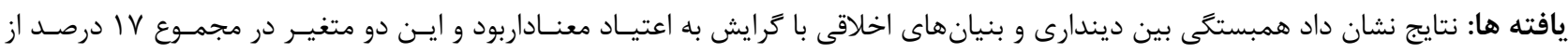

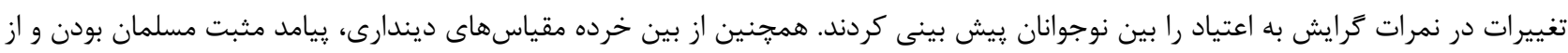

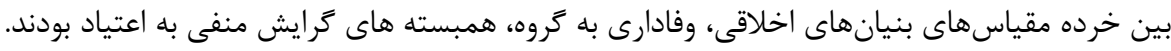

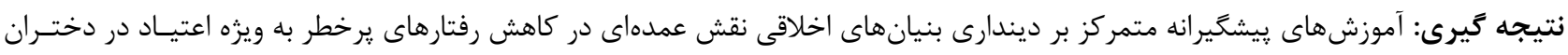
نوجوان ايفا مى كند.

كليدوازه: كرايش به اعتياد، بنيانهاى اخلاقى، ديندارى، نوجوانى 
نظريه بنيان هاى اخلاقى مبتنى بــر اخـلاق شهودوى اسـت كـه در

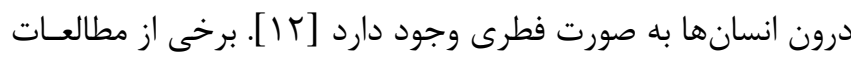

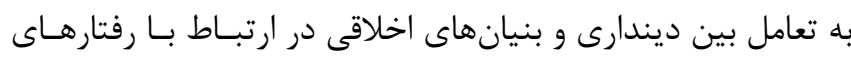
سوء مصرف مواد مخدر اشاره كرده و تفاوت تـاثيرات آن را ناشسى از رسومات اجتماعى و سطوح اخلاقى متفاوت افراد در جامعاد دانسـته

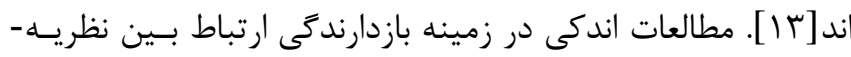

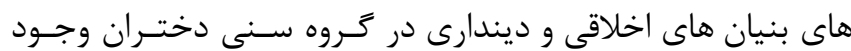

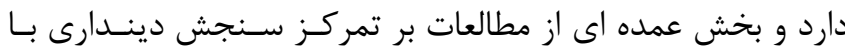

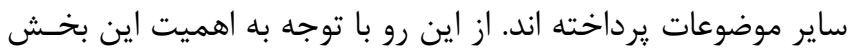

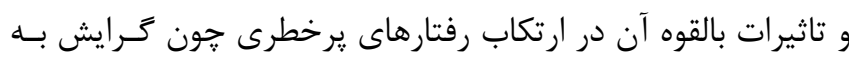

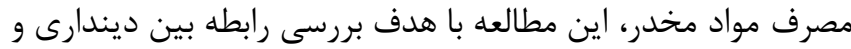
بنيان هاى اخلاقى با گرايش به اعتياد در دختران نوجوان شهر تهران

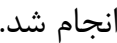

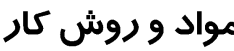

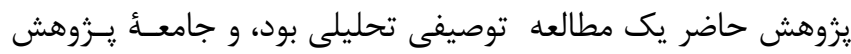

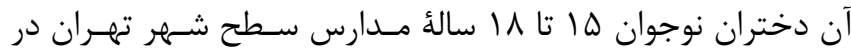

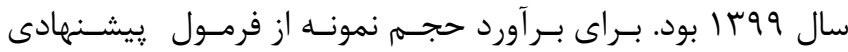

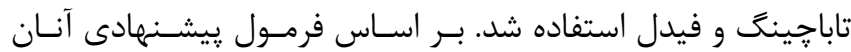
حداقل حجم نمونه در مطالعات همبستخى از فرمول N N

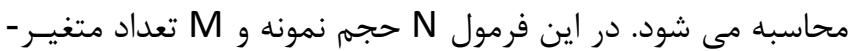

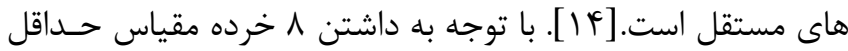

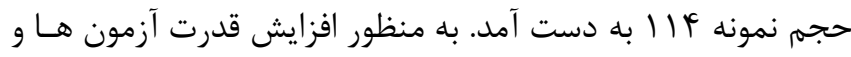

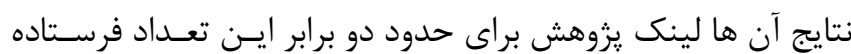

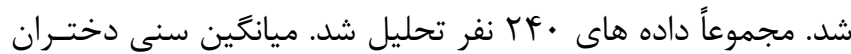

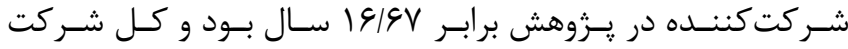
كنند

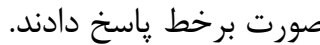
مقياس نكرش مسلمانان به دين: اين مقياس أع أ كويه دارد و وايلد و جوزف آن را براى سنجش نخرش مسلمانان به اسلام ساختهاند. اين

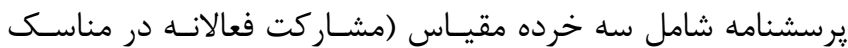

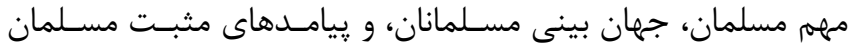

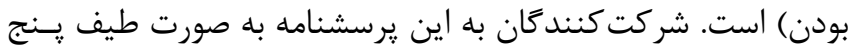

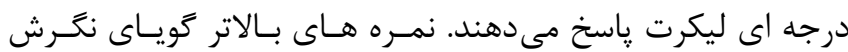

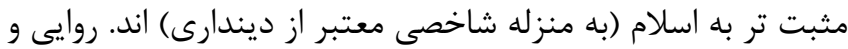
بايايى مقياس در ميان دانشجويان ايرانى تاييد شده است. [1 إ].

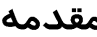

امروزه گرايش به مصرف مواد به طور گسترده اى يك مشكل جـدى در سطح جهان شــاخته مسىشـود و يِيامـدهاى روانسى و جسـمانى بسيارى براى كروههاى در معرض خطر به ويـزّه نوجوانـان دارد [1].

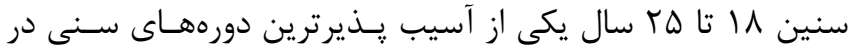

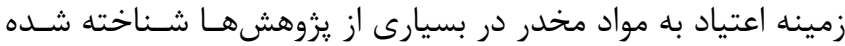

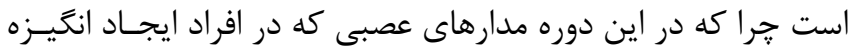

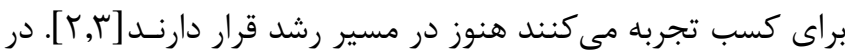

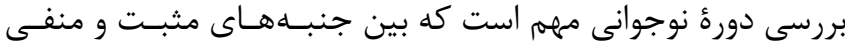

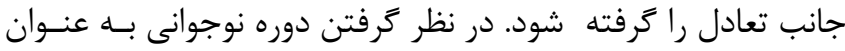

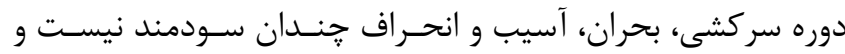

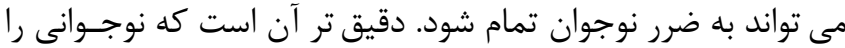

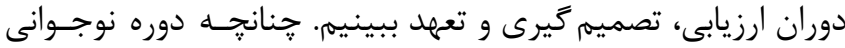

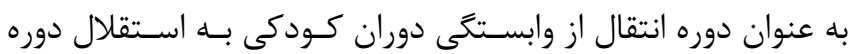
جوانى و بزركسالى شناخته مىشود. ايـن خـروه بــه علـت تغييـرات

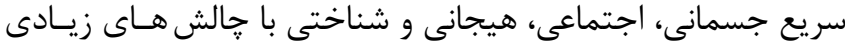

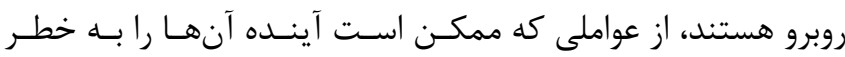
بياندازد مصرف و گرايش به مواد مخدر است [F]

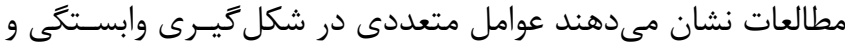

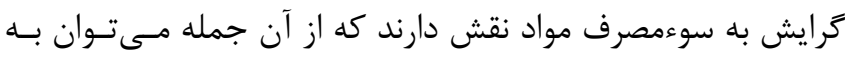

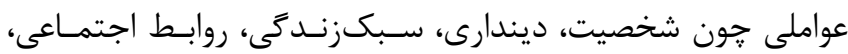
نكَرش، اخلاق، باورها، احساسات، و دلبستكى ها اشاره كرد [ه]]. ديـن به عنوان يكى از مهمترى عوامل ياد شده، از راه برقرارى يـك نظـهم

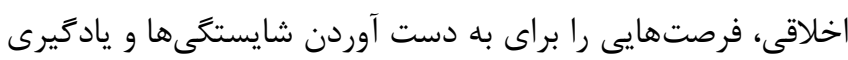

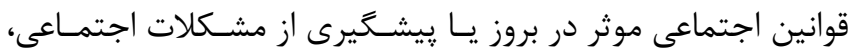

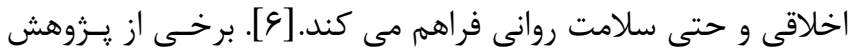
ها به رابطه معكوس ميان ديندارى و ترايش به مصرف مــواد اشـاره

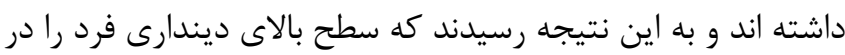

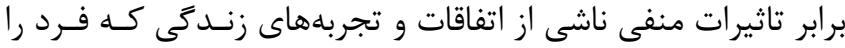

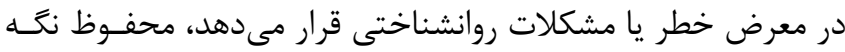

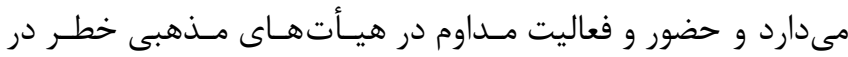

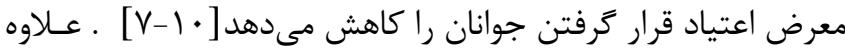

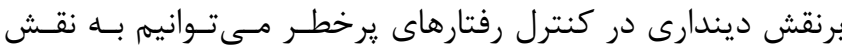
بازدارندكى اخلاق در كرايش به مواد مخدر اشاره كرد. اخيراً نظريه بنيانهاى اخلاقى مورد توجه روانشناسان و ورئ متخصصـان ساير حوزه ها قرار كرفته است[11] 
متغيرها با استفاده از فرمول جولنى و كشيدگى تاييد شده اسـت، از

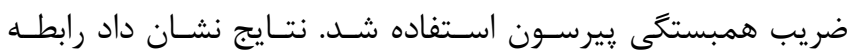

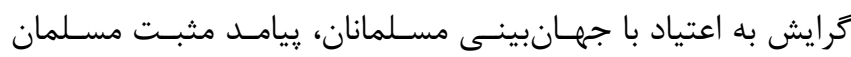

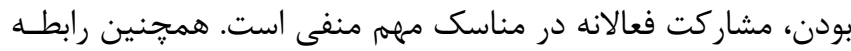

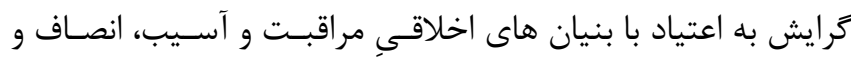

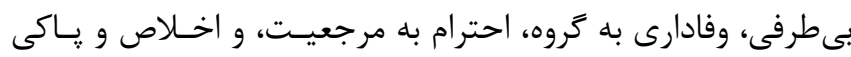

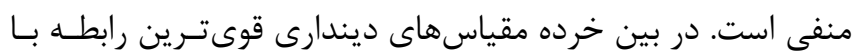
كرايش به اعتياد مربوط به يِامد مثبت مسلمان بودن و ضعيفترين

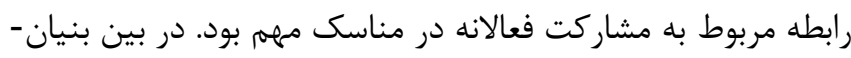

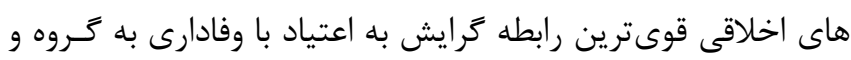

$$
\text { ضعيفترين رابطه با مراقبت و آسيب بود (جدول (1). }
$$

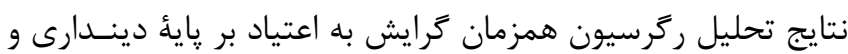

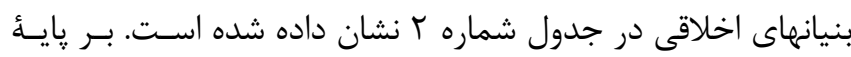
IV اين نتايج، خردهمقياسهاى ديندارى و بنيانهاى اخلاقى دركل درصد از تغييرها در نمرههاى كرايش به اعتياد را تبيـين مسى كننـد.

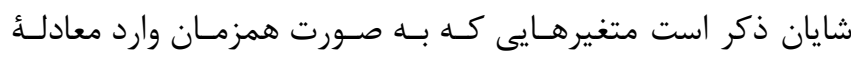

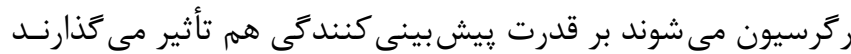

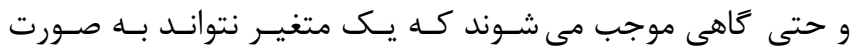

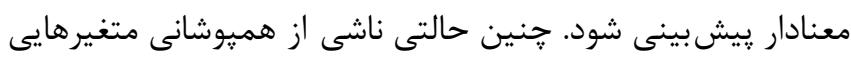
است كه وارد معادله ركر سيون شدهاند.

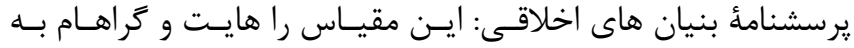

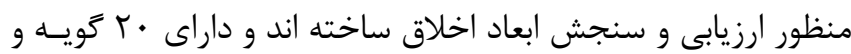

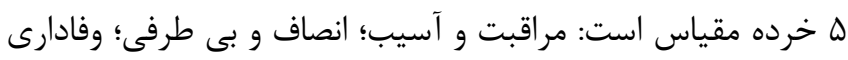

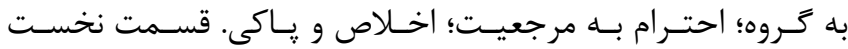

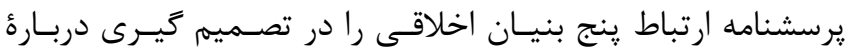

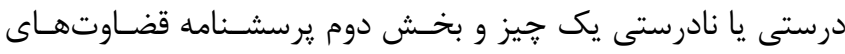

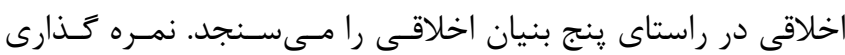
بخش اول به صورت طيف ينج درجه است. نمره هاى بـالاتر در هـر

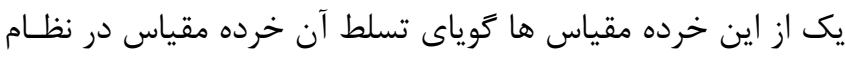

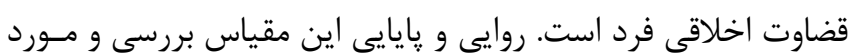
تاييد قرار گرفته است [11]

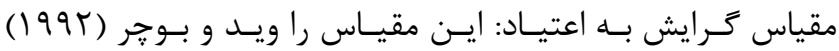

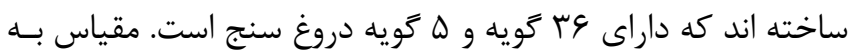

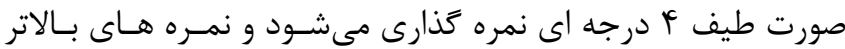

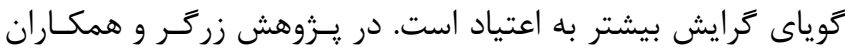

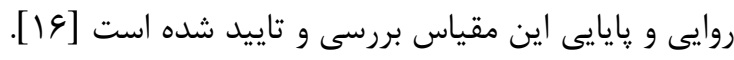

بافتهها

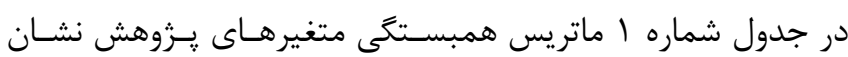

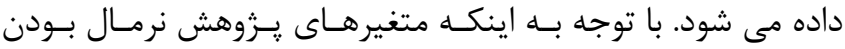

جدول ا: ضرايب همبستكى متغيرها

\begin{tabular}{|c|c|c|c|c|c|c|c|c|c|c|}
\hline 9 & $\wedge$ & v & 9 & $\Delta$ & $F$ & $r$ & r & 1 & & \\
\hline & & & & & & & & 1 & I. كرايش به اعتياد & \\
\hline & & & & & & & 1 & - & r. جهان بينى به دين & \\
\hline & & & & & & 1 & 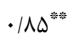 & 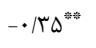 & r. بِيامد مثبت مسلمان بودن & 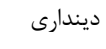 \\
\hline & & & & & 1 & $\cdot|\Delta|^{* * a}$ & $\cdot|\Delta|^{m * n}$ & $-\cdot / r \Delta^{\text {sth }}$ & f. مشاركت فعالانه در مناسك مهمم & \\
\hline & & & & 1 & .1 .9 & $\cdot / 1$ & $\cdot 119^{*}$ & $-\cdot /\left.1\right|^{* *}$ & 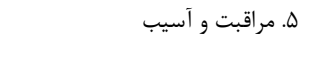 & \\
\hline & & & 1 & $\cdot / 4 \Lambda^{* * \%}$ & $\cdot / 14^{*}$ & $\cdot / 1 V^{* * * *}$ & $\cdot / \pi 9^{\text {m*n }}$ & $-\cdot / r \varphi^{* * * m}$ & צ. انصاف و بى طرفى & \\
\hline & & 1 & $\cdot / \mathrm{q}^{* * *}$ & 每 & $\cdot / T V^{* * *}$ & $\cdot / r V^{* * * * 4}$ & $\cdot / A T^{2}$ & $-\cdot / r \Lambda^{* * * w^{*}}$ & V. وفادارى به كروه & بنيانهــــاى \\
\hline & 1 & $\cdot / 4 F^{m=0}$ & · & $\cdot / r \cdot \stackrel{* m}{* m}$ & · & $\cdot / 4 \cdot \cdot^{* * * 4}$ & 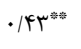 & $-\cdot / r \Delta^{* * m}$ & ^. احترام به مرجعيت & \\
\hline 1 & 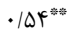 & $\cdot|\Delta|^{\frac{m a}{m a}}$ & 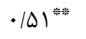 & $\cdot / 44^{\frac{* 0}{*}}$ & $\cdot / r^{* * * *}$ & 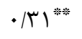 & $\cdot / \Gamma q^{\text {क*:* }}$ & $-\cdot / T \Delta^{\text {粪 }}$ & 9. اخلاص و پاكى & \\
\hline
\end{tabular}


سال بيستم، شماره اول، بهمن ـ اسفند 99\%1

جدول r: خلاصه نتيجه ركر سيون پييش بينى كرايش به اعتياد

\begin{tabular}{|c|c|c|c|c|c|c|c|c|}
\hline سطح معنى دارى & $\mathbf{T}$ & SD & B & Beta & $\mathrm{R}^{2}$ & $\mathbf{F}$ & متغيرهاى بيش بين & متغير ملاك \\
\hline $.1 . \cdot 1$ & r r/r/T &.$/ 14$ &.$- / 49$ & $-\cdot / \pi T$ & \multirow{2}{*}{$\cdot / / V$} & \multirow{2}{*}{$r \Delta / \Delta \Delta$} & ديندارى & \multirow{2}{*}{ كرايش به اعتياد } \\
\hline $.1 . .1$ & ג ו ג/r- & r & $-\cdot / \Delta r$ &.$- / 48$ & & & بنيان هاى اخلاقى & \\
\hline
\end{tabular}

مخدر در نوجوانان دختـر دارد. باورهـاى مـذهبى همراسـتا بـا ايـن مطالعه نقش بازدارنده قوى در تمايل به مصـرف مـواد در نوجوانـان بوده است، هر جزند كه در اين قبيل از مطالعات بر نقـش ييونـدهاى

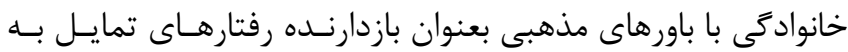

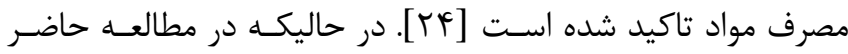

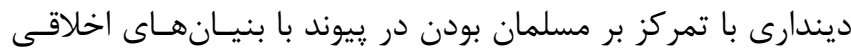
نقش قابل توجهى در كاهش رفتارهاى مصرف مواد داشته اند.

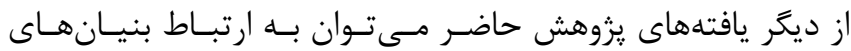

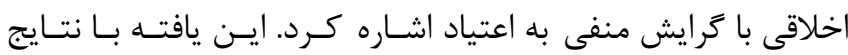

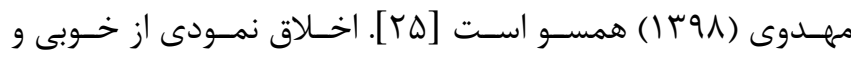
ويزگگ هاى درونى انسان است كه منشاء رفتارهاى انسانى است. هـر جه بنيانهاى اخلاقى فرد استوارتر باشند امكان رفتن به سمت مــواد

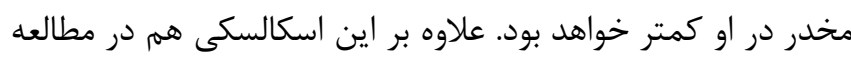

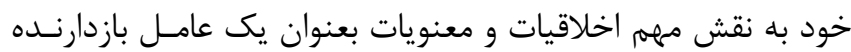

در رفتارهاى گرايش به مصرف مواد اشاره داشته است [111].

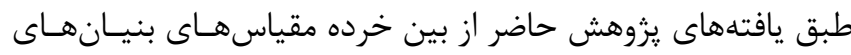

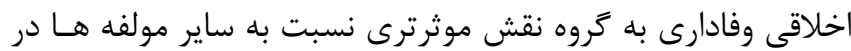
كاهش گرايش به اعتياد نوجوانان دختر داشـت. برخـى از مطالعـات

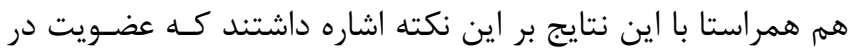

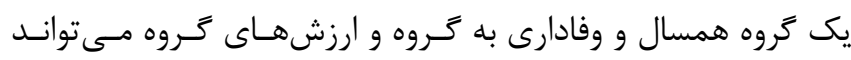
نقش تعيين كنندهاى در كرايش به رفتار سوء مصـرف مــواد داشـته

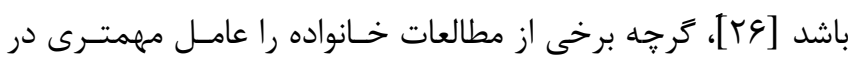

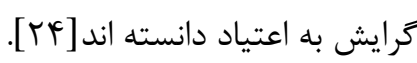

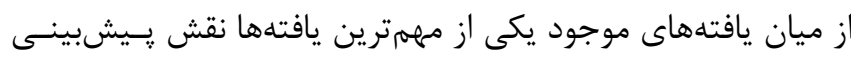
كنندكى بنيان هاى اخلاقى و ديندارى در كرايش منفـى بـ بـهـ اعتيـاد

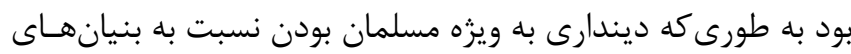

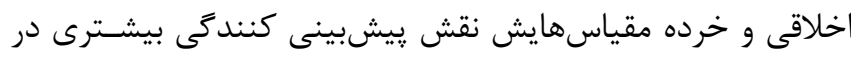
كرايش دختران نوجوان به اعتياد و سوء مصرف مواد داشت. از ميان

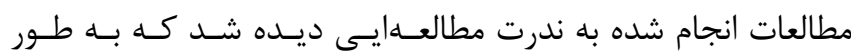

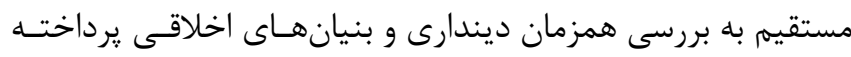

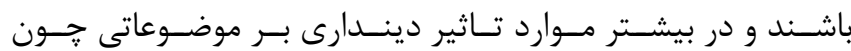

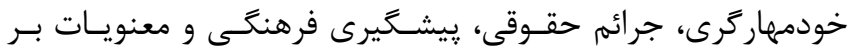

\section{بحث و نتيجه گيرى}

اين يروهش نشان داد بين دختران نوجـوان دينــارى و بنيـانهـاى اخلاقى با گرايش به اعتياد ارتباط منفى دارنـد. افـزايش دينــدارى و

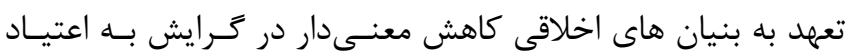

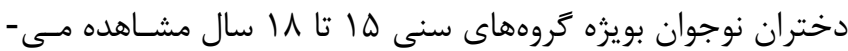
شود. اين نتيجه از يروهش حاضر همسو با يافتههاى عجمسى ، بـور ،

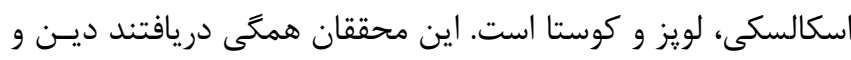

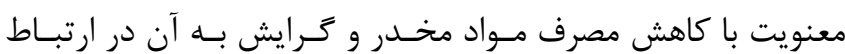

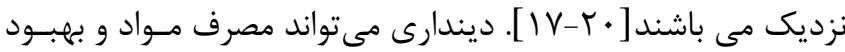

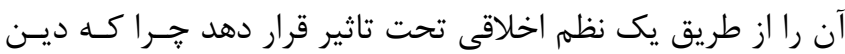
قواعد خاص اخلاقى را به منظور خويشتندارى در اختيار فـرد قـرار مى دهد و اين تجربه معنوى مسىتوانـد تعهـدات اخلاقىى را تحكـيمى

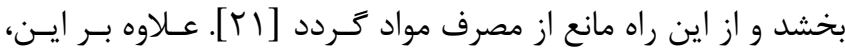

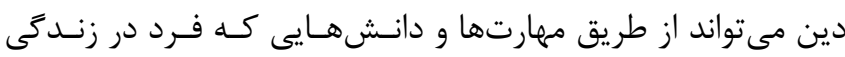

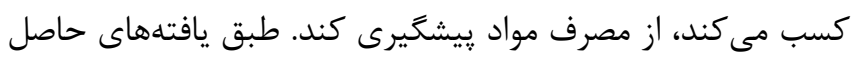

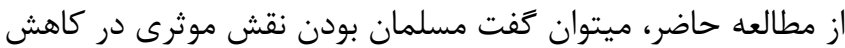

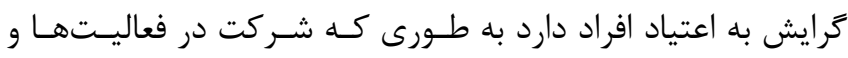

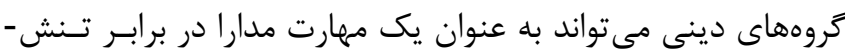
هاى زندگى عمل كند. افراد در زندگى روزانه خود بر يايـه باورهـاى شخصى و ديدگاهى كه درباره ديخران دارند، رفتـار مسى كنـــد. ايسن

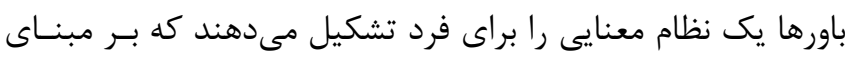

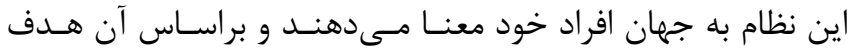

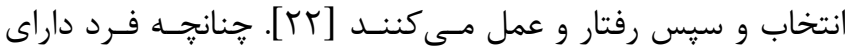
سطح ديندارى بيشترى باشد ديدگاهى كه از خود و جهان اطــرافش

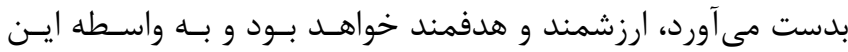
هدفمندى احتمال كمترى دارد كه به رفتارهايى مانند مصرف مـواد

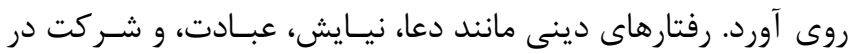

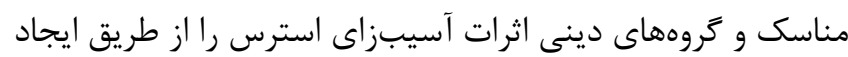

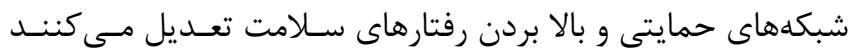

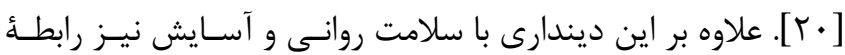

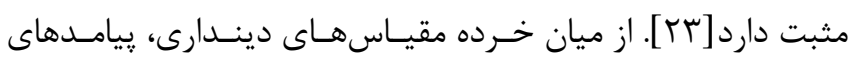

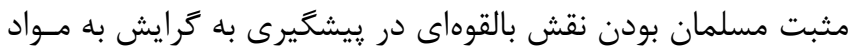




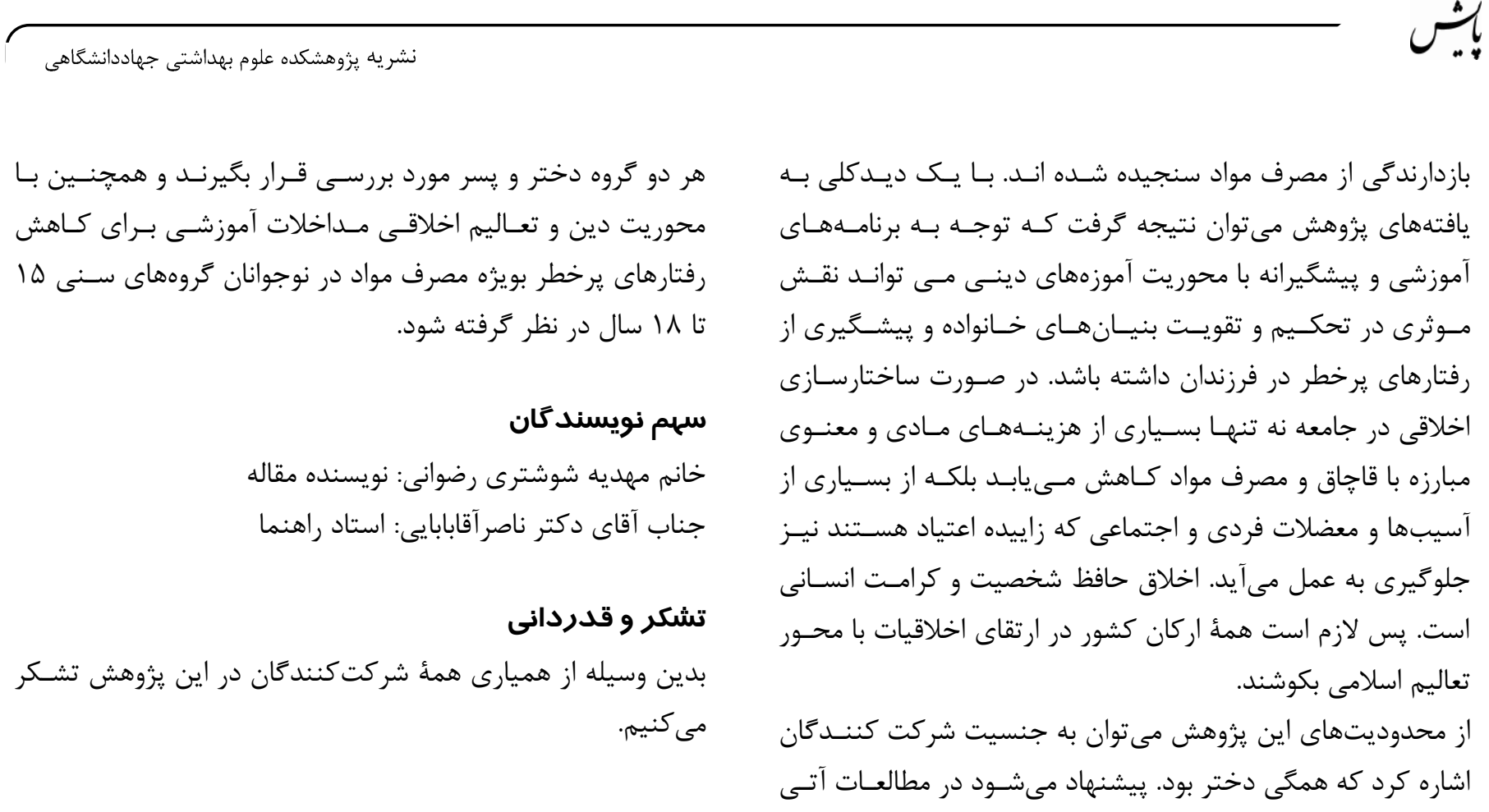

\section{منابع}

1. Lopes O, Costa J. Drugs and Religion: Contributions to the Debate on the Science-Religion Interface. Religions 2018;9:136

2. McCabe SE, Morales M, Cranford JA, Delva J, McPherson MD, Boyd CJ. Race/ethnicity and gender differences in drug use and abuse among college students. Journal of ethnicity in substance abuse 2007; 17;6:75-95

3. Sawyer SM, Afifi RA, Bearinger LH, Blakemore SJ, Dick B, Ezeh AC, Patton GC. Adolescence: a foundation for future health. The lancet 2012; 28:1630-40

4. Esmaeilpour K, Farzaneh A. Prediction of Emotional and Educational Adjustment of Students Based on Family Functioning Dimensions. Journal of Instruction and Evaluation 2019; 11: 103-118 [Persian]

5. Stone AL, Becker LG, Huber AM, Catalano RF. Review of risk and protective factors of substance use and problem use in emerging adulthood. Addictive Behaviors 2012; 1;37: 747-75

6. Yonker JE, Schnabelrauch CA, DeHaan LG. The relationship between spirituality and religiosity on psychological outcomes in adolescents and emerging adults: A meta-analytic review. Journal of Adolescence 2012; 1;35: 299-314

7. Smith C, Faris R, Denton ML, Regnerus M. Mapping American adolescent subjective religiosity and attitudes of alienation toward religion: A research report. Sociology of Religion 2003 1;64: 111-33

8. Skalski LM, Martin B, Meade CS. Sexual Orientation, Religious Coping, and Drug Use in a Sample of HIV-Infected African-American Men Living in the Southern USA. Journal of Religion and Health 2019; 58: 1368-81

9. Bever MB. Religious Coping and Christ-Centered Recovery for Women with Substance Use Disorders. 2019

10. Kaviani Mobarakeh A. The Impact of Religious Boards on Youth Tendency to Drug from a Criminological Perspective. Journal of Cultural Engineering 2015; 85: 50-71 [Persian]

11. Graham J, Haidt J, Koleva S, Motyl M, Iyer R, Wojcik SP, Ditto PH. Moral foundations theory: The pragmatic validity of moral pluralism. In Advances in Experimental Social Psychology 2013; 47: 55-130.

12. Haidt J, Joseph C. Intuitive ethics: How innately prepared intuitions generate culturally variable virtues. Daedalus 2004; 133: 55-66

13. Ghorbani N, Watson P. J, Ghramaleki A. F, Morris R. J, \& Hood R. W, Jr. Muslim Attitudes Towards Religion Scale: Factors, validity, and complexity of relationships with mental health in Iran. Mental Health, Religion, \& Culture 2000; 3, 125-132

14. Tabachnick BG, Fidell LS. Using multivariate statistics. Boston: Allyn \& Bacon/Pearson Education; 2007

15. Aghababaei N, Sohrabi F, Eskandari H, Borjali A, Farrokhi N, \& Chen ZJ. Predicting subjective wellbeing by religious and scientific attitudes with hope, 
purpose in life, and death anxiety as mediators. Personality and Individual Differences 2016; 90: 9398

16. Zargar Y. Construction and Validation of Iranian Scale for Addiction Readiness. Proceeding of the 2nd Congress on Psychology, 2006: Tehran, Iran [Persian] 17. Ajami M. Qasemzadeh D. Beri Ajirloo f. And Faramarzi s. Investigating the Relationship between Individual Religiosity and Prevention of Industrial Drug Abuse among Last Year High School Students in Tabriz, 2nd National Conference on Sociology and Social Sciences, Tehran, Narkish Information Institute, 2014 [Persian]

18. Bever MB. Religious Coping and Christ-Centered Recovery for Women with Substance Use Disorders. DNP Scholarly Projects 2019; 16

19. Skalski LM, Martin B, Meade CS. Sexual Orientation, Religious Coping, and Drug Use in a Sample of HIV-Infected African-American Men Living in the Southern USA. Journal of Religion and Health 2019; 58:1368-1381

20. Lopes O, \& Costa J. Drugs and Religion: Contributions to the Debate on the Science-Religion Interface. Religions 2018; 9: 136
21. Smith C. Theorizing religious effects among American adolescents. Journal for the Scientific Study of Religion 2003; 42: 17-30

22. Silberman I. Religion as a meaning system: Implications for the new millennium. Journal of Social Issues 2005; 61: 641-63

23. Aghababaei, N. The relations among religiosity, subjective well-being, and attitudes towards science. International Journal of Behavioral Sciences 2018; 12: 65-69

24. Taremian F, Jazayeri A, Ghasi tabataei SM. Psychosocial Predicting Factors of Drug Use among Adolescents: Applicability of "Peer Group Theory" among Iranian Adolescents. Scientific, Research Journal of Zanjan University of Medical Sciences2013; 85: 108-120 [Persian]

25. Mahdavi GH, Qayyumzadeh M. Ethical structuring in cultural prevention of drug addiction. Journal of Ethical Research 2017; 1:3 [Persian]

26. Salami F, Hatami H.R, Noori R. Structural model of substance use tendency in adolescents based on psychological family climate and family history of addiction with mediating peer group. Journal of Applied Psychology 2018; 2: 265-284 [Persian] 